\title{
REVIEW \\ Effects of Side Vents and Span Numbers on Wind-Induced Natural Ventilation of a Gothic Multi-Span Greenhouse
}

\author{
Murat KACIRA $^{1,2}$, Sadanori SASE ${ }^{2 *}$ and Limi OKUSHIMA ${ }^{2}$ \\ ${ }^{1}$ Department of Agricultural Machinery, Faculty of Agriculture, Harran University (Sanliurfa, Turkey) \\ ${ }^{2}$ Department of Agricultural Environment Engineering, National Institute for Rural Engineering \\ (Tsukuba, Ibaraki 305-8609, Japan)
}

\begin{abstract}
In this paper, the effects of wind speed, side ventilators and span numbers on gothic type multi-span greenhouse natural ventilation were studied by numerical simulation using the Computational Fluid Dynamics (CFD) approach. The realizable k- $\varepsilon$ model was used for the turbulence model in the simulations. The results showed that the maximum greenhouse ventilation rate was achieved when both side and roof vents were used for ventilation. Without the existence of buoyancy effect in the computations, it was found that the ventilation rate increased linearly with the external wind speed in all the cases studied. The ratio of the opening of the ventilator area to the greenhouse floor area, $9.6 \%$, was found to be small compared to the recommended ratios of $15-25 \%$. The results showed that a significant reduction in ventilation rate was determined as the number of spans was increased and an exponential decay explained the relationship between the ventilation rate and the number of spans.
\end{abstract}

Discipline: Agricultural facilities

Additional key words: CFD, greenhouse design, optimization

\section{Introduction}

In recent years, there has been a trend in Japan, mainly due to economic considerations, to build large multi-span greenhouses. In these greenhouses, the openings are located usually on the roof and do not occasionally have side walls. The effects of side vents and greenhouse span numbers on natural ventilation are not clearly known by growers and greenhouse manufacturers. In order to achieve proper ventilation rates as well as the uniformity of environment, however, the ratio of vent opening area to greenhouse floor area must be chosen properly and a change to ventilation by a combination of roof and side openings are considered to be essential.

Proper ventilation performance is crucial for greenhouses in both humid winter climates and hot summer conditions. The ventilation process contributes to optimal control of air temperature, humidity, and concentra- tion of gases in the greenhouse interior climate. Thus, photosynthetic and transpiration activities of plants are regulated properly and quality of the crops is improved. Precise knowledge of greenhouse ventilation performances could enable the minimum surface of the openings to be determined and thus, decrease the risk of overheating in the summer periods.

Due to several advantages, natural ventilation is usually the only air renewal process in protected cultivation. However, control of airflow with natural ventilation is limited. Therefore, it is necessary to analyze natural ventilation properly and increase ventilation efficiency.

Natural ventilation is driven by pressure differences created at the vent openings both by wind and/or temperature differences. It has been reported that winds stronger than $2 \mathrm{~m} \mathrm{~s}^{-1}$ dominate the ventilation process and in this case the effect of air temperature difference could be neglected ${ }^{1,7,10}$. Buoyancy driven ventilation is more important if the wind speeds, $\mathrm{u}$, are lower than $0.5 \mathrm{~m} \mathrm{~s}^{-1}$.

This paper reports the results obtained in the project "CFD and wind tunnel tests on natural ventilation of greenhouses and its effect on crop microclimate" sponsored by Japanese Society for the Promotion of Science.

*Corresponding author: fax +81-29-838-7609; e-mail sase@nkk.affrc.go.jp

Received 11 May 2004; accepted 1 June 2004. 
In the intermediate cases where $0.5 \mathrm{~m} \mathrm{~s}^{-1}<\mathrm{u}<2 \mathrm{~m} \mathrm{~s}^{-1}$, the ventilation is driven mostly by the wind effect and some influence of the buoyancy is observed ${ }^{7}$.

The phenomenon involved in natural ventilation is very complex and designing of a naturally ventilated greenhouse is complex as well. Direct measurements of air velocity, air exchange rates, and flow patterns are difficult and expensive. Thus, indirect methods have been used as alternatives such as energy balance models, tracer gas methods, and wind-buoyancy effect numerical models. The advancement in computer speed and technology enabled researchers to apply numerical simulations using Computational Fluid Dynamics (CFD) as a new tool to study greenhouse aerodynamics. Compared to the indirect methods, it is much more flexible for the researcher to study the effects of different boundary conditions (given as environmental conditions) on airflow patterns, temperature distributions inside and outside the greenhouse, and on air exchange rates in a much faster and cost effective way.

There has been tremendous interest in studying greenhouse ventilation using CFD applications. Kacira et al. ${ }^{5}$ studied the effect of side and roof vent configurations on air exchange rates of sawtooth greenhouse designs. Mistriotis et al. ${ }^{7,8}$ evaluated the efficiency of greenhouse ventilation with two-dimensional cases for Mediterranean-type greenhouses. Boulard et al. ${ }^{2,3}$ studied airflow distribution and ventilation characteristics of naturally ventilated greenhouses. Lee and Short ${ }^{6}$ determined the effects of air velocities and directions on ventilation rates of a multi-span quonset greenhouse.

The majority of the previous studies on natural ventilation using CFD applications evaluated airflow patterns and ventilation rates with small scale greenhouses. Only a few studies are available for large scale multispan greenhouses. Therefore, the aim of this paper is to determine the effects of wind speed, side vent and greenhouse span numbers on natural ventilation and airflow characteristics of gothic type multi-span greenhouses which are becoming popular for greenhouse plant production in Japan.

\section{Materials and methods}

\section{Description of the numerical method}

The modeled transport equations for $\mathrm{k}$ and $\varepsilon$ in the realizable $\mathrm{k}-\varepsilon$ model are:

$$
\begin{aligned}
& \frac{\partial}{\partial \mathrm{t}}(\rho \mathrm{k})+\frac{\partial}{\partial \mathrm{x}_{\mathrm{i}}}\left(\rho \mathrm{ku} \mathrm{u}_{\mathrm{j}}\right) \\
& =\frac{\partial}{\partial \mathrm{x}_{\mathrm{i}}}\left[\left(\mu+\frac{\mu_{\mathrm{t}}}{\sigma_{\mathrm{k}}}\right) \frac{\partial \mathrm{k}}{\partial \mathrm{x}_{\mathrm{j}}}\right]+\mathrm{G}_{\mathrm{k}}+\mathrm{G}_{\mathrm{b}}-\rho \varepsilon-\mathrm{Y}_{\mathrm{M}}+\mathrm{S}_{\mathrm{k}}
\end{aligned}
$$

and,

$$
\begin{aligned}
& \frac{\partial}{\partial \mathrm{t}}(\rho \varepsilon)+\frac{\partial}{\partial \mathrm{x}_{\mathrm{j}}}\left(\rho \varepsilon \mathrm{u}_{\mathrm{j}}\right) \\
& =\frac{\partial}{\partial \mathrm{x}_{\mathrm{j}}}\left[\left(\mu+\frac{\mu_{\mathrm{t}}}{\sigma_{\varepsilon}}\right) \frac{\partial \varepsilon}{\partial \mathrm{x}_{\mathrm{j}}}\right]+\rho \mathrm{C}_{1} \mathrm{~S}_{\varepsilon}-\rho \mathrm{C}_{2} \frac{\varepsilon^{2}}{\mathrm{k}+\sqrt{v \varepsilon}} \\
& +\mathrm{C}_{1 \varepsilon} \frac{\varepsilon}{\mathrm{k}} \mathrm{C}_{3 \varepsilon} \mathrm{G}_{\mathrm{b}}+\mathrm{S}_{\varepsilon}
\end{aligned}
$$

where:

$$
\mathrm{C}_{1}=\max \left[0.43, \frac{\eta}{\eta+5}\right], \eta=\mathrm{S} \frac{\mathrm{k}}{\varepsilon}
$$

In these equations, $G_{k}$ represents the generation of turbulence kinetic energy due to the mean velocity gradient, $G_{b}$ is the generation of turbulence kinetic energy due to buoyancy, $\mathrm{Y}_{\mathrm{M}}$ represents the contribution of the fluctuating dilatation in compressible turbulence to the overall dissipation rate, and $\mathrm{C}_{2}$ and $\mathrm{C}_{1 \varepsilon}$ are constants. $\sigma_{\mathrm{k}}$ and $\sigma_{\varepsilon}$ are the turbulent Prandtl numbers for $\mathrm{k}$ and $\varepsilon$, respectively.

The realizable $\mathrm{k}-\varepsilon$ model is a relatively recent development and differs from the standard $k-\varepsilon$ model in two important ways:

- The realizable k- $\varepsilon$ model contains a new formulation for the turbulent viscosity.

- A new transport equation for the dissipation rate, $\varepsilon$, has been derived from an exact equation for the transport of the mean-square vorticity fluctuation.

The term "realizable" means that the model satisfies certain mathematical constraints on the Reynolds stresses, consistent with the physics of turbulent flows. An immediate benefit of the realizable k- $\varepsilon$ model is that it more accurately predicts the spreading rate of both planar and round jets. It is also likely to provide superior performance for flows involving rotation, boundary layers under strong adverse pressure gradients, separation, and recirculation. Both the realizable and RNG k- $\varepsilon$ models have shown substantial improvements over the standard $k-\varepsilon$ model where the flow features include strong streamline curvature, vortices, and rotation ${ }^{4}$.

\section{Validation of the CFD model with experimental data}

The validation of the CFD model used in this paper was carried out using the experimental wind tunnel data reported by Okushima et al. ${ }^{9}$. Okushima et al. ${ }^{9}$ studied the wind effects on airflow patterns in a Venlo type greenhouse using the Particle Image Velocimetry (PIV) technique and hot wire anemometers. The research was conducted using a 1/12 scale two-span Venlo greenhouse model in a wind tunnel. The original dimensions and configuration of vent openings of the greenhouse used in 
Okushima et al. ${ }^{9}$ and in the validation of the CFD model in this paper are shown in Fig. 1. Only windward roof vents were open at an angle of $45^{\circ}$.

The greenhouse described above was numerically studied by CFD simulation using the same dimensions and wind speeds studied in the wind tunnel experiments. The simulations were done with external wind speed of $3.0 \mathrm{~m} \mathrm{~s}^{-1}$. The buoyancy effect was not considered in the simulations since the wind speeds which were tried were in the intermediate and high wind speed levels, $0.5 \mathrm{~m} \mathrm{~s}^{-1}$ $<\mathrm{u}<2 \mathrm{~m} \mathrm{~s}^{-1}$, thus the ventilation and airflow is driven mostly by the wind effect ${ }^{6}$.

Fig. 2 illustrates the comparisons of the CFD results with Okushima et al. ${ }^{9}$ for air velocities at the roof openings. Furthermore, Fig. 3 shows the comparison of airflow pattern in the greenhouse. The results illustrated in Fig. 2 and 3 showed that a good quantitative agreement was obtained between numerical simulation by CFD

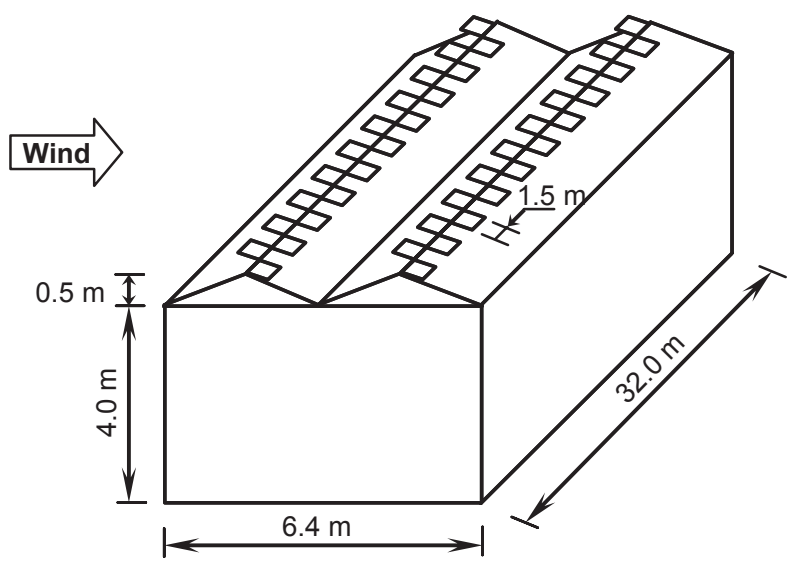

Fig. 1. Schematic diagram of the experimental greenhouse used in Okushima et al. (1998)

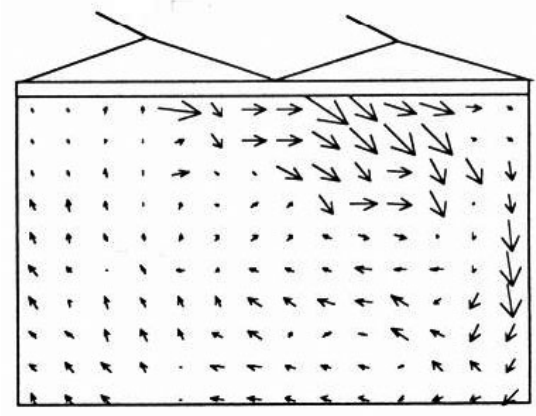

(a) model and experimental results of Okushima et al. ${ }^{9}$ confirming the validity of the model used in the simulations.

\section{Simulation cases for multi-span gothic greenhouses}

After validating the CFD model with previously reported experimental data reported by Okushima et al. ${ }^{9}$, the simulations were carried out for evaluating the effect of wind speed and number of spans on natural ventilation characteristics of gothic greenhouses in terms of ventila-

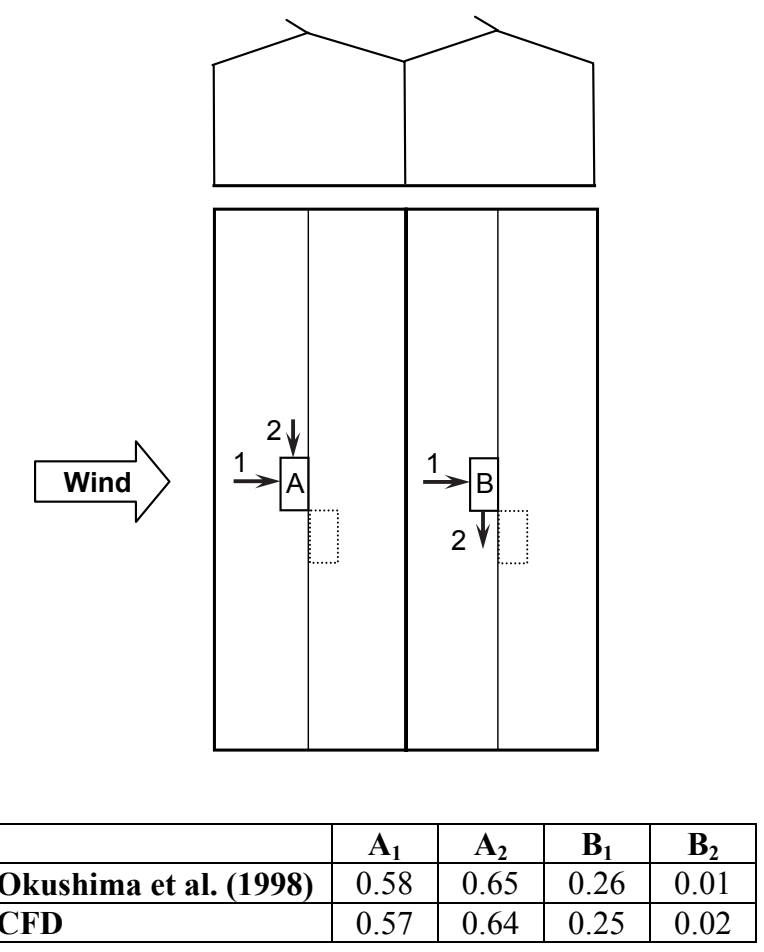

Fig. 2. The comparison of air velocities at the roof openings between wind tunnel results (Okushima et al., 1998) and CFD simulations

Only windward roof vents are open.

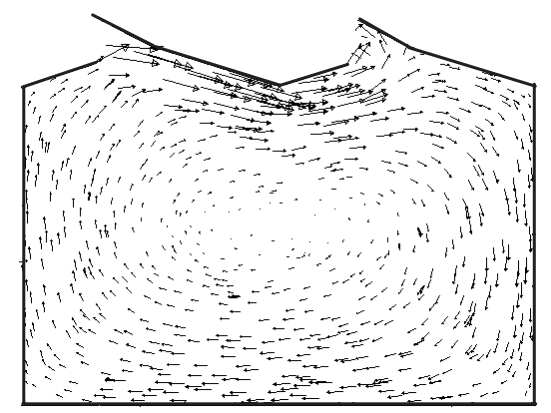

(b)

Fig. 3. The comparison of airflow pattern in the Venlo greenhouse between (a) wind tunnel results (Okushima et al., 1998) and (b) CFD simulations 


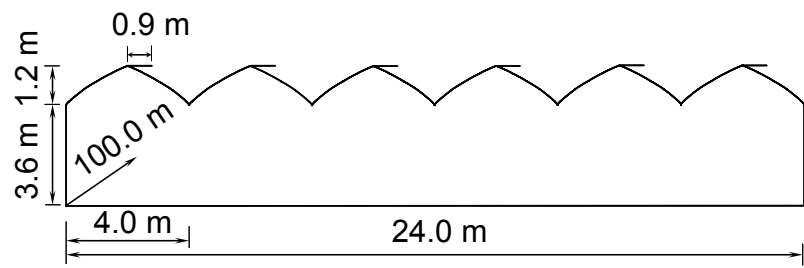

Fig. 4. Schematic diagram of a 6-span gothic greenhouse used in the simulations

tion rates and airflow patterns. Fig. 4 illustrates the physical dimensions and design of the gothic greenhouse used in the simulations. The greenhouse used in the simulations was selected from the Sedia System Greenhouse Company catalog in Japan (WBFC House). This greenhouse design is recently becoming popular and is being preferred by Japanese growers for its large volume and space for production.

The width of each span was $4.0 \mathrm{~m}$, the height of the gutter was $3.6 \mathrm{~m}$ and the total height of the greenhouse was $4.8 \mathrm{~m}$. The length of the greenhouse was selected to be $100 \mathrm{~m}$. The effect of exterior wind speed on ventilation rate and greenhouse airflow pattern was evaluated with wind speeds ranging from 0.5 to $3.5 \mathrm{~m} \mathrm{~s}^{-1}$ with an increment of $1.0 \mathrm{~m} \mathrm{~s}^{-1}$. In this study, only the effect of external wind approaching from the windward side was evaluated. The external wind profile was generated as a logarithmic wind profile providing $0.5,1.5,2.5$, and 3.5 $\mathrm{m} \mathrm{s}^{-1}$ wind speeds at a height of $10 \mathrm{~m}$ outside the greenhouse. The effect of span numbers on natural ventilation characteristics of this greenhouse was determined using $6,12,18$, and 24 span greenhouses. A 6-span greenhouse provided a greenhouse growing area of 0.24 ha. The effect of windward and leeward side vents for greenhouse ventilation was also analyzed. The side vents were fully open in the fully open side and roof vent cases. The maximum angle of the roof vent opening is the horizontal position of the roof vents.

The simulations were done using a $3 \mathrm{D}$ computational domain with the realizable $\mathrm{k}-\varepsilon$ turbulence model as described earlier in this paper. The buoyancy effect was not considered in the simulations since the wind speeds studies were in the intermediate $\left(0.5 \mathrm{~m} \mathrm{~s}^{-1}<\mathrm{u}<2 \mathrm{~m} \mathrm{~s}^{-1}\right)$ and high wind speed levels $\left(\mathrm{u}>2 \mathrm{~m} \mathrm{~s}^{-1}\right)$, thus the ventilation and airflow is driven mostly by the wind effect ${ }^{6}$.

The ventilation rate defined as number of air exchanges per minute was calculated using the simulation results as:

$$
\mathrm{V}_{\mathrm{R}}=\frac{\dot{\mathrm{m}}}{\rho_{\mathrm{air}} \mathrm{V}} 60
$$

Where, $V_{R}$ is ventilation rate defined as air exchanges (AE) per minute $\left(\mathrm{AE} \mathrm{min}^{-1}\right), \dot{\mathrm{m}}$ is the mass flow rate $(\mathrm{kg}$ $\left.\mathrm{s}^{-1}\right), \rho_{\text {air }}$ is the density of the air $\left(\mathrm{kg} \mathrm{m}^{-3}\right)$, and $\mathrm{V}$ is the volume of the greenhouse $\left(\mathrm{m}^{3}\right)$.

\section{Results and discussion}

\section{The effect of wind speed on ventilation rate}

Fig. 5a and 5b illustrate the relationship between external wind speed and ventilation rates for fully open windward and leeward side vents and roof vents, and for only roof vents in the cases for four different span numbers evaluated, respectively. Without the existence of buoyancy effect in the computations, it was found that the ventilation rate increases linearly with the external wind speed in all the cases studied. The ventilation rate ranged from 0.6-4.7 (6-Span), 0.3-2.4 (12-Span), 0.21.5 (18-Span), and $0.16-1.1 \mathrm{AE} \mathrm{min}^{-1}$ (24-Span) for the wind speeds varying from 0.5 to $3.5 \mathrm{~m} \mathrm{~s}^{-1}$ in the fully open windward and leeward side vents and roof vents cases. Furthermore, the ventilation rate ranged from 0.03-0.24 (6-Span), 0.025-0.19 (12-Span), 0.024-0.17 (18-Span), and $0.023-0.16 \mathrm{AE} \min ^{-1}$ (24-Span) for the wind speeds varying from 0.5 to $3.5 \mathrm{~m} \mathrm{~s}^{-1}$ in the cases of greenhouses equipped with only roof vents. The rate of change in ventilation rate among the span numbers under different wind speeds in the cases of greenhouses equipped with only roof vents were found to be much less than those ratios determined in the fully open windward and leeward side vents and roof vents cases. The ratio of the opening of the ventilator area to the greenhouse floor area was $9.6 \%$ for all the cases evaluated. This opening size was selected in the computations based on the growers common practice used in this particular greenhouse design. However, it is well known and documented that for design purposes and achievement of appropriate ventilation rates, the total area of openings is recommended to be $15-25 \%$ of the floor area of the greenhouse in general. The ratio of $9.6 \%$ used with this particular greenhouse design for ventilation in greenhouse production is much less compared to the recommended opening ratio. Thus, it does not provide high enough ventilation rates especially when only roof vents are used for the ventilation process.

\section{The effect of span numbers on the ventilation rate}

In this study the effect of span numbers on the ventilation rate was evaluated with four different span numbers; $6,12,18$, and 24 span cases. Fig. $6 \mathrm{a}$ and $6 \mathrm{~b}$ show the relationship between span numbers and ventilation rates for the fully open windward and leeward side vents, and roof vents and for only roof vents cases, respectively, 

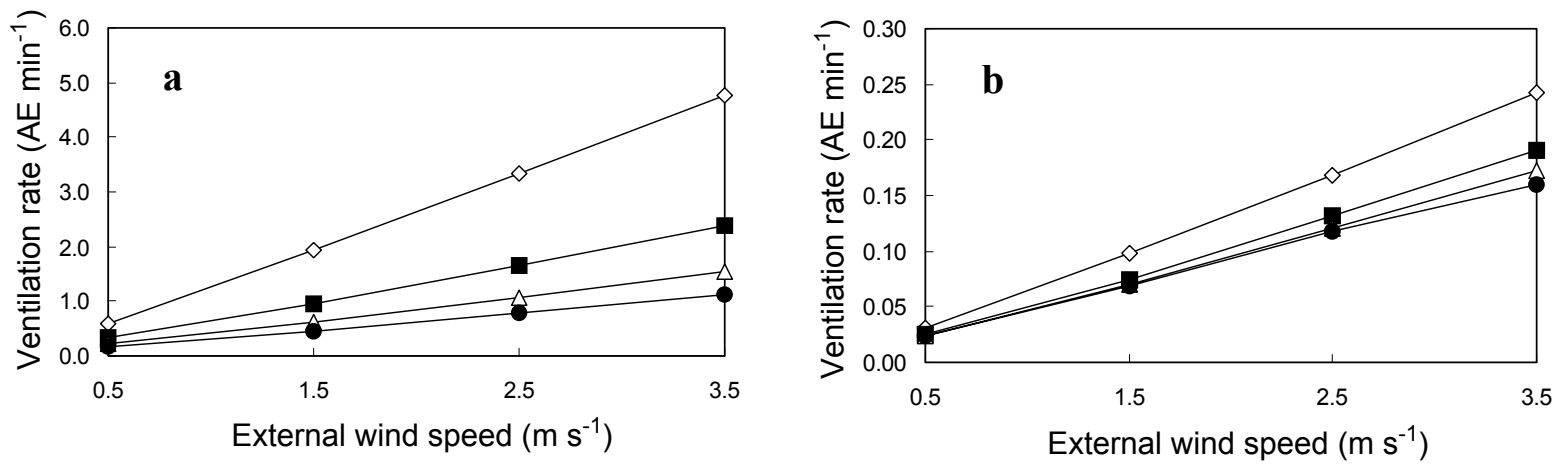

Fig. 5. The effect of windward side external wind speed on greenhouse ventilation rate for different span numbers

a: Fully open windward and leeward side vents and roof vents.

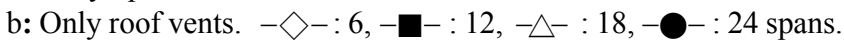
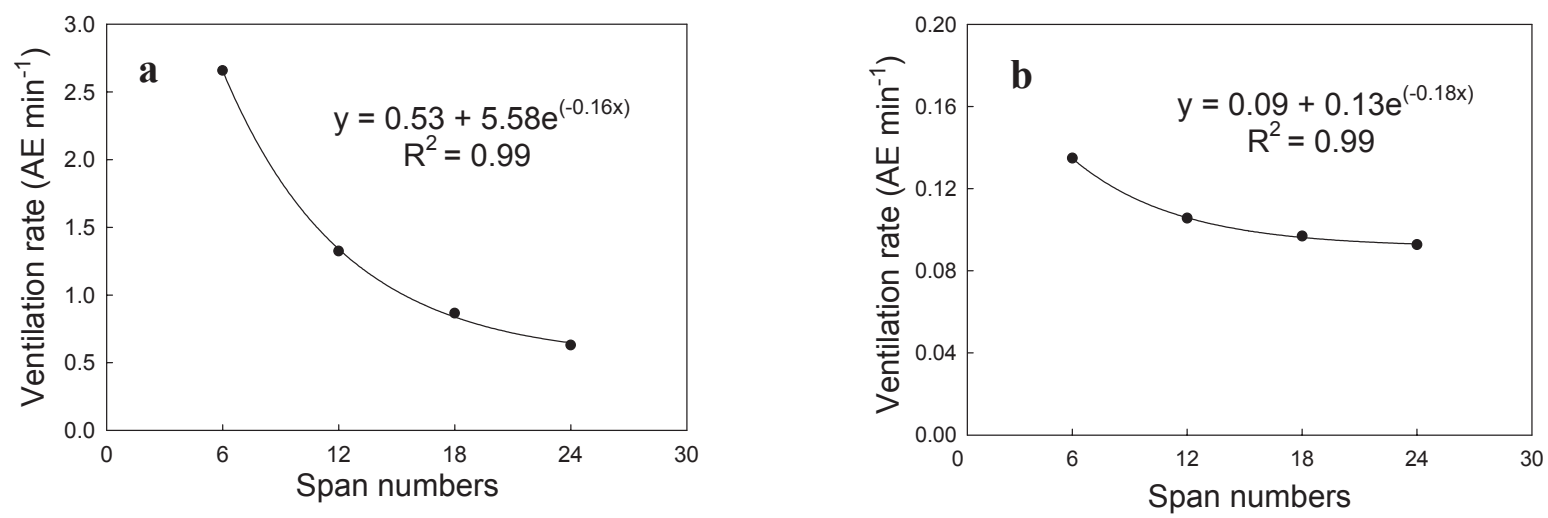

Fig. 6. The effect of number of spans on greenhouse ventilation rate

a: Fully open windward and leeward side vents and roof vents. b: Only roof vents.

for an average external wind speed of $2 \mathrm{~m} \mathrm{~s}^{-1}$ (averages of four external wind speeds evaluated in this study). The results showed that the ventilation rate decreased exponentially as the span numbers were increased from 6 to 24. A significant reduction of ventilation rate in the fully open windward and leeward side vents and roof vents cases was observed as the number of spans is increased. One of the reasons for this could be due to the fact that the ratio of side vent area and floor area was reduced as the span number was increased, when the side vent area was constant. The ventilation rate did not seem to be dependent on span numbers in the fully open roof vent cases. The decrease in ventilation rates was found to be too small as the span numbers were increased. The reason for the decrease in ventilation rates might be due to inappropriate size of vent opening area compared to floor area and the creation of reversed airflow in the greenhouse as the span numbers are increased. The occurrence of reverse flow in the greenhouse with the increased span numbers is shown in the next section in the paper. The maximum ventilation rates in naturally ventilated green- houses are achieved when the area of the vent openings where the air comes in equals the area of the vent openings where the air moves out. When this balance is changed, the maximum ventilation rates may not be obtained for a particular greenhouse design and vent configurations. This was observed in the cases with only fully open roof vents when the span number is increased.

\section{The effect of span numbers on the greenhouse airflow pattern}

One of the aims of this study was to determine the effect of span numbers on the airflow pattern in the greenhouse interior. Fig. 7 illustrates the vector plot of airflow pattern in the 6-span greenhouse case equipped with the fully open windward and leeward side vents and roof vents. Most of the air entered from the windward side vents and flowed through the greenhouse interior and the majority of the outflow occurred from the leeward side vent. The outflow of the air from the roof vents were less compared to those from the leeward side vent. Similar airflow pattern was obtained for all the 


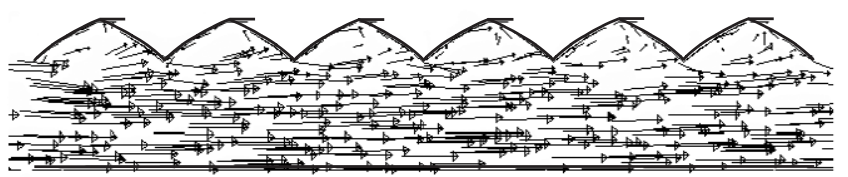

Fig. 7. The effect of side vent opening on the airflow pattern in a 6-span greenhouse

The external wind speed is $0.5 \mathrm{~m} \mathrm{~s}^{-1}$.

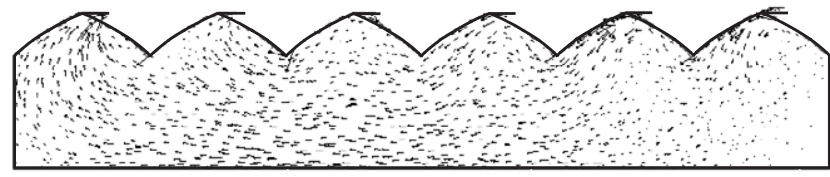

Fig. 8. The airflow pattern in a 6-span greenhouse without the side vents

The external wind speed is $0.5 \mathrm{~m} \mathrm{~s}^{-1}$.

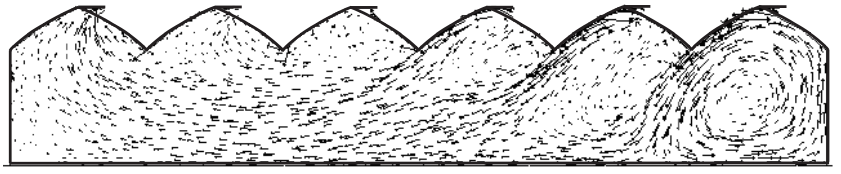

Fig. 9. The airflow pattern in a 6-span greenhouse without the side vents

The external wind speed is $3.5 \mathrm{~m} \mathrm{~s}^{-1}$.

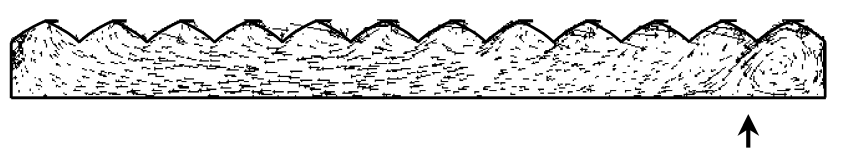

Fig. 10. The airflow pattern in a 12-span greenhouse without the side vents

The external wind speed is $3.5 \mathrm{~m} \mathrm{~s}^{-1}$.

Arrow indicates the point of reversed flow.

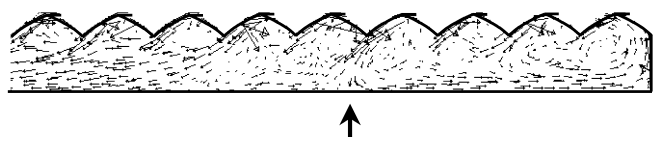

Fig. 11. The airflow pattern in an 18-span greenhouse without the side vents

The external wind speed is $3.5 \mathrm{~m} \mathrm{~s}^{-1}$.

Arrow indicates the point of reversed flow.

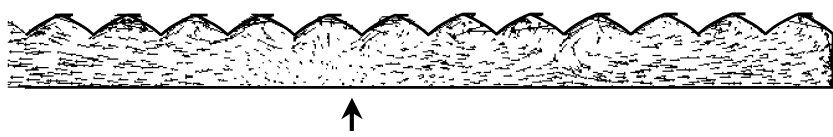

Fig. 12. The airflow pattern in a 24-span greenhouse without the side vents

The external wind speed is $3.5 \mathrm{~m} \mathrm{~s}^{-1}$.

Arrow indicates the point of reversed flow. cases evaluated with different external wind speeds studied in this paper. The contribution of side vents on the ventilation rate and the airflow pattern in the greenhouse was found to be significant.

When the side vents were fully closed and only roof vents were opened, the air velocity in the greenhouse was reduced dramatically (Fig. 8). The interior air was pulled up towards the roof vents because of the pressure difference created between the exterior of the greenhouse along the roof openings and inside the greenhouse ceiling. In the case of $0.5 \mathrm{~m} \mathrm{~s}^{-1}$ external wind speed, the air entered the greenhouse from the last 4 spans of the greenhouse, traveled along the greenhouse interior towards the windward side of the greenhouse and the outflow occurred from the first 2 roof vents from the windward side.

When the external wind speed was increased, the air entered the greenhouse from the last 3 spans of the greenhouse, traveled along the greenhouse interior towards the left side of the greenhouse and most of the outflow occurred from the first roof vent from the windward side (Fig. 9). In this case, the occurrence of an air vortex was also observed in the $6^{\text {th }}$ span of the greenhouse. In such cases, there is expected to be less air renewal in the canopy zone of the $6^{\text {th }}$ span. Furthermore, higher greenhouse air temperatures, in this particular zone compared to the other zones in the greenhouse, are to be expected. A similar airflow pattern was also obtained in the 12 span case (Fig. 10). A reverse flow and air vortex was observed in the $12^{\text {th }}$ span of the greenhouse. The airflow was found to be more stagnant and air velocities were much less along the $8^{\text {th }}$ and $11^{\text {th }}$ spans in the greenhouse. The reason for this might be due to the number of the spans and the creation of the reverse flow in the $12^{\text {th }}$ span. When the span numbers were further increased from 12 to 18 spans, the reverse airflow started from the $15^{\text {th }}$ span in the greenhouse and the airflow was found to be more stagnant in the $13^{\text {th }}$ and $14^{\text {th }}$ spans (Fig. 11). In the case of 24 spans, the occurrence and starting point of the reverse airflow is further moved towards the center of the greenhouse $\left(16^{\text {th }}\right.$ span) (Fig. 12).

\section{Conclusions}

In this paper, the effects of wind speed, side vent and greenhouse span numbers on natural ventilation and airflow characteristics of gothic type multi-span greenhouses which are becoming popular in Japan were studied by numerical simulations using the CFD approach. The realizable k- $\varepsilon$ model was used for the turbulence model in the computations. The CFD model used in the study was validated using the experimental 
results of a previous study. The greenhouse ventilation rates were determined along with the airflow patterns for each case studied.

The results of ventilation rates showed that the maximum greenhouse ventilation rate was achieved when both side and roof vents are used for ventilation. Without the existence of buoyancy effect in the computations, it was found that the ventilation rate increased linearly with the external wind speed in all the cases studied. The ratio of the opening of the ventilator area to the greenhouse floor area, $9.6 \%$, was found to be small compared to the recommended ratios of $15-25 \%$.

The results showed that the ventilation rate decreased exponentially as the span numbers were increased from 6 to 24 when both side vents were fully open. A significant reduction in ventilation rate was observed as the number of spans was increased. This was attributed to the inappropriate size of vent opening area compared to floor area and the creation of reversed airflow in the greenhouse as the span numbers were increased. The contribution of side vents on the ventilation rate and the airflow pattern in the greenhouse was found to be significant.

The great importance of both side and roof ventilators for an efficient ventilation was illustrated. The above results could provide useful hints to designers of greenhouse frames or greenhouse control systems. However, one must keep in mind that the CFD results discussed in this paper concern empty greenhouses. Thus, they offer a rough picture of the ventilation process in a real greenhouse where the plants and the internal structural elements also alter the internal airflow. Further investigations might be required for obtaining a simpli- fied but realistic representation of the plants and blocking elements in CFD simulations. The authors believe that these computational results will stimulate and guide future direction in CFD simulations and experimental research for greenhouse ventilation.

\section{References}

1. Bot, G. P. A. (1983) Greenhouse climate: from physical process to a dynamic model. $\mathrm{PhD}$ dissertation, Agricultural University of Wageningen, Wageningen, The Netherlands, pp.240.

2. Boulard, T. et al. (1997) Airflow and associated sensible heat exchanges in a naturally ventilated greenhouse. Agric. For. Meteorol., 88, 111-119.

3. Boulard, T. et al. (1999) Characterization and modeling of the air fluxes induced by natural ventilation in a greenhouse. J. Agric. Eng. Res., 74, 135-144.

4. Fluent Inc. (1998) Fluent user guide, Version 6.2.1, Fluent Inc., Lebanon, NH.

5. Kacira, M. et al. (1998) A CFD evaluation of naturally ventilated, multi-span sawtooth greenhouses. Trans. ASAE, 41(3), 833-836.

6. Lee, I. \& Short, T. H. (2000) Two-dimensional numerical simulation of natural ventilation in a multi-span greenhouse. Trans. ASAE, 43(3), 745-753.

7. Mitriotis, A. et al. (1997a) Computational analysis of ventilation at zero and low wind speeds. Agric. For. Meteorol., 88, 121-135.

8. Mitriotis, A. et al. (1997b) Analysis of the efficiency of greenhouse ventilation using computational fluid dynamics. Agric. For. Meteorol., 85, 217-228.

9. Okushima, L. et al. (1998) Airflow patterns forced by wind effect in a Venlo type greenhouse. J. Soc. Agric. Struct. Jpn., 29(3), 59-67.

10. Papadakis, G. et al. (1996) Measurement and analysis of air exchange rates in a greenhouse with continuous roof and side openings. J. Agric. Eng. Res., 63, 219-228. 